\title{
En mann i 60-årene med hjerteinfarkt, stenttrombose og blødning
}

\author{
En pasient ble innlagt fire ganger på tre uker pga. hjerteinfarkt \\ og residiverende okklusjon av venstre fremre koronararterie. Kombina- \\ sjon av blødning og trombose vanskeliggjorde adekvat behandling.
}

Se kommentar side 616 og kunnskapsprøve på www.tidsskriftet.no/quiz

\author{
Trygve B. Tjugen* \\ trygve.braathen.tjugen@siv.no \\ Jan Eritsland \\ Arild Mangschau \\ Hjertemedisinsk avdeling \\ Oslo universitetssykehus, Ullevål \\ 0407 Oslo

\section{Geir Øystein Andersen} \\ Hjertemedisinsk avdeling \\ og \\ Senter for klinisk hjerteforskning \\ Oslo universitetssykehus, Ullevål
}

\author{
* Nåværende adresse: \\ Anestesiologisk avdeling \\ Sykehuset i Vestfold
}

\begin{abstract}
En mann i 60-årene kontaktet 113 på grunn av akutt innsettende retrosternale smerter med utstråling til hals. Tidligere hadde han gjennomgått et hjerteinfarkt. Det var ingen kjent hjerte- og karsykdom i slekten, men han hadde kardiale risikofaktorer i form av langvarig sigarettrøyking, overvekt og hypertensjon. Pasienten brukte acetylsalisylsyre, betablokker, angiotensin II-blokker og et statin. Før aktuell innleggelse hadde han vært plaget med angina pectoris ved anstrengelse i en måneds tid. Prehospitalt EKG viste ST-hevning i avledning V1-V4 med resiprok ST-senkning i avledning II, aVF og III. På grunn av kort sykehistorie, EKG-forandringer og lang transporttid til sykehus med perkutan koronar intervensjon (PCI), besluttet man å gi pasienten prehospital trombolytisk behandling, to timer og 20 minutter etter smertedebut. Han ble deretter fraktet til sitt lokalsykehus. Pasienten fikk i tillegg $300 \mathrm{mg}$ klopidogrel og $300 \mathrm{mg}$ acetylsalisylsyre. En time etter behandlingen så man vedvarende ST-hevning i V1-V4 og pasienten ble ikke smertefri. Han ble derfor flyttet til Oslo universitetssykehus, Ullevål for såkalt redningsangioplastikk (rescue-PCI).
\end{abstract}

Brystsmerter med typiske EKG-forandringer (ST-hevning eller nyoppstått venstre grenblokk) gir mistanke om akutt okklusjon av koronarkar og bør medføre rask behandling. Det er svært viktig å få åpnet det okkluderte koronarkaret så fort som mulig. Valget står mellom primær mekanisk (PCI) og medikamentell (trombolytisk) reperfusjonsbehandling avhengig av geografiske forhold og symptomvarighet. Pasienten bør uansett behandles med acetylsalisylsyre, klopidogrel og oksygen samt nitroglyserin og morfin etter behov (1). Redningsangioplastikk (PCI etter antatt mislykket trombolytisk behandling) vurderes ved vedvarende ST-hevning og brystsmerter 60-90 minutter etter igangsatt trombolytisk behandling (1).

Ved ankomst Oslo universitetssykehus, Ullevål var pasienten smertefri. Han hadde arterielt blodtrykk på 130/100 mm Hg og det ble bemerket obstruktive pipelyder og basale krepitasjoner over begge lungeflater. Ved koronar angiografi påviste man rikelig med kalk i koronarkarene, tre signifikante stenoser i høyre koronararterie, veggforandringer $i$ arteria circumflexa, en signifikant stenose og tromber i proksimale venstre fremre koronararterie samt en signifikant stenose $i$ midtre del. Det ble utført PCl med implantasjon av konvensjonell metallstent i proksimale og midtre venstre fremre koronararterie med godt angiografisk resultat. Under prosedyren fikk pasienten vektjustert dose av ufraksjonert heparin intravenøst. Røntgen thorax viste stuvningsforandringer, og pasienten fikk nitroglyserininfusjon og diuretika intravenøst som hjertesviktbehandling. Man målte troponin T til $19 \mu \mathrm{g} / \mathrm{l}$ (normalt $<0,10 \mu \mathrm{g} / \mathrm{l}$ ), kreatinkinase (CK) til 5000 $\mathrm{U} / \mathrm{l}$ (referanseverdi 40-280 U/l), mens trombocyttallet var $210 \times 10^{9} /$ l (referanseverdi $145-390 \times 10^{9} / \mathrm{ll}$ og hemoglobin $15,2 \mathrm{~g} / \mathrm{dl}$ (referanseverdi $13,7 \mathrm{~g} / \mathrm{dl}$ ). Orienterende ekkokardiografi viste utbredt infarktområde apikalt og i distale del av venstre ventrikkels fremre vegg. ST-hevningen på EKG gikk tilbake etter prosedyren. Påfølgende natt fikk pasienten nye brystsmerter.

Nye brystsmerter etter PCI-behandling skal alltid gi mistanke om reokklusjon av be- handlet koronararterie. Pasienter som ikke ligger med kontinuerlig overvåking av STsegmentet, bør ved nye brystsmerter raskt få tatt et nytt EKG, og deretter må man vurdere indikasjon for ny øyeblikkelig hjelp koronar angiografi.

Nytt EKG viste nytilkomne ST-hevninger i fremreveggsavledningene som ga mistanke om reokklusjon av behandlet koronararterie. Ny koronarangiografi viste okkluderende trombe ved inngangen til stenten og i hele det tidligere stentede området (fig 1). Man valgte à gi ufraksjonert heparin og abciximab (en glykoprotein IIb/IIla-hemmer) samt utføre ny $\mathrm{PCl}$ med stenting av proksimale venstre fremre koronararterie. Det angiografiske resultatet var godt, pasienten ble raskt smertefri og det tilkom ingen ny økning i CK eller troponin $T$.

Akutt stenttrombose (innen 24 timer etter PCI) forekommer sjelden (0,1-0,2\%) (2). Frekvensen av subakutte stenttromboser (1-30 dager etter PCI) er hyppigere og ligger på $1-3 \%(2-3)$. Vår pasient hadde typiske symptomer og tegn på reokklusjon av koronarkar, som ble bekreftet ved koronarangiografi. I henhold til europeiske retningslinjer (1) anbefales glykoprotein IIb/ IIIa-hemmer når det påvises større tromber og mistanke om perifer embolisering under PCI ved akutt hjerteinfarkt. Abciximab er best dokumentert og gis som en vektjustert bolusdose etterfulgt av kontinuerlig infusjon i 12 timer for å motvirke ytterligere trombosering. Andre glykoprotein IIb/IIIa-hemmere kan også brukes. Ved noen sentre brukes glykoprotein IIb/IIIa-hemmere rutinemessig ved PCI av akutt ST-hevningsinfarkt. Gevinsten av dette ved optimal ladningsdose med acetylsalisylsyre og klopidogrel er omdiskutert (1).

Pasienten ble overflyttet til lokalsykehus påfølgende dag for videre behandling med betablokker, acetylsalisylsyre, klopidogrel, statin og protonpumpehemmer. Ufraksjonert heparin og abciximab var seponert. På lokalsykehuset fikk pasienten subkutane injeksjoner av lavmolekylært heparin. Få dager etter infarktet utviklet han makroskopisk hematuri og urinretensjon. Man la derfor inn et treveis skyllekateter i urinblæren. CT abdomen viste en stor tumor i urinblæren med mistanke om gjennombrudd til omkringliggende vev, men uten at det ble påvist metastasesuspekte lesjoner. 


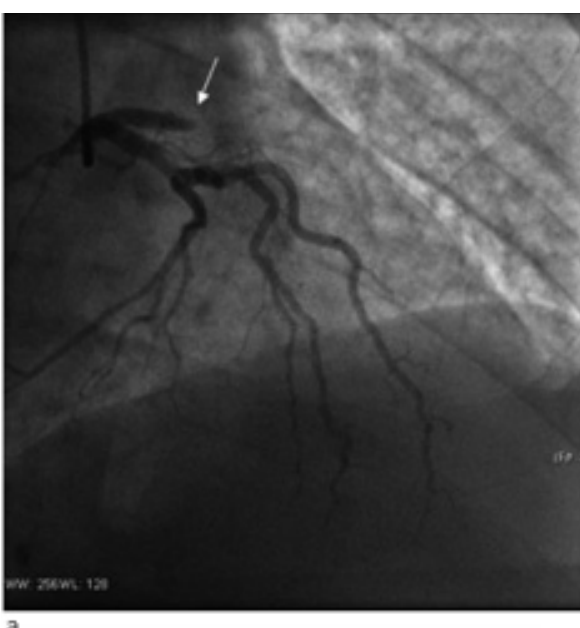

a

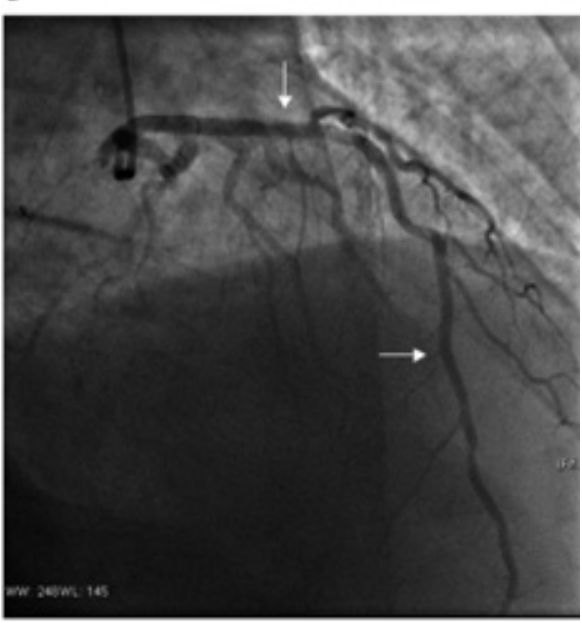

b

Figur 1 Selektiv koronarangiografi hos en mann i 60-årene med nye brystsmerter få timer etter utført akutt angioplastikk av venstre fremre koronararterie i forløpet av et akutt ST-hevningsinfarkt. a) Okkludert venstre fremre koronararterie (hvit pil) (stenttrombose) før akutt angioplastikk. b) Venstre fremre koronararterie (hvit pil) etter intervensjon med åpning av den okkluderte arterien

For best mulig å forhindre ny stenttrombose etter hjerteinfarktet fikk pasienten behandling med tre ulike platehemmende prinsipper i tillegg til lavmolekylært heparin. Dette, sammen med en mistenkt malign sykdom i urinblæren, forårsaket høyst sannsynlig hematuri. Pasienter med malign sykdom kan dels ha en hyperkoagulabel tilstand og dels øt blødningstendens (4). En liten, retrospektiv studie har konkludert med sju ganger høyere risiko for stenttrombose i koronarkar hos pasienter med malign sykdom.

Det ble besluttet å seponere klopidogrel en uke etter infarktet pga. fare for stor blødning og blæretamponade. Lokalsykehuset valgte å beholde acetylsalisylsyre og lavmolekylært heparin, da man mente at en potensiell stor urinveisblødning var lettere å håndtere ved denne kombinasjonen enn ved bruk av klopidogrel. Det ble planlagt transurethral biopsi og tumorreseksjon etter noen dager. Dag 11 etter første hjerteinfarkt ble pasienten for- søkt overflyttet til sykehus med urologisk senter for biopsitaking. Under ambulansetransporten fikk pasienten på nytt sterke brystsmerter, og EKG viste nye ST-hevninger i fremreveggsavledninger. Transporten ble avbrutt og pasienten ble $i$ stedet fraktet til Oslo universitetssykehus, Ullevål for ny akutt koronarangiografi. Her fant man for andre gang en nytilkommet trombotisk okklusjon av stenten i venstre fremre koronararterie. Det ble utført ballongdilatasjon med implantasjon av konvensjonell metallstent. Klopidogrel ble gjeninnsatt, mens lavmolekylært heparin ble seponert. Man ga ufraksjonert heparin under prosedyren, men ikke glykoprotein IIb/IIla-hemmer. Denne gangen var troponin T-verdien $2 \mu \mathrm{g} / \mathrm{l}$, hemoglobin $11 \mathrm{~g} / \mathrm{dl}$ og trombocytter $160 \times 10^{9} / \mathrm{l}$.

Ettersom malign sykdom er assosiert med både hyperkoagulabilitet og blødning, kan antitrombotisk behandling etter PCI hos slike pasienter være komplisert. Etter retningslinjene valgte man ved første koronare intervensjon acetylsalisylsyre i kombinasjon med klopidogrel (1), men da pasienten fikk blødning fra urinveiene, ble klopidogrel seponert. I etterkant kan det diskuteres om denne behandlingen burde vært opprettholdt til tross for risiko for alvorlige blødingskomplikasjoner og påvist blæretumor (5). Seponering av klopidogrel var sannsynligvis medvirkende årsak til denne stenttrombosen. Etter to tilfeller av stenttrombose anså man at det var små muligheter for å holde stenten i venstre fremre koronararterie åpen uten å påføre pasienten stor blødningsrisiko. Det ble derfor besluttet å tilby ham rask aortokoronar bypassoperasjon, men av hensyn til nylig gjennomgått hjerteinfarkt ønsket man å vente i 1-2 uker. I mellomtiden ble han på ny behandlet med acetylsalisylsyre og klopidogrel. Biopsitaking av mistenkt malign lesjon i urinblæren ble utsatt pga. stor blødningsrisiko inntil man kunne seponere klopidogrel.

Pasienten ble flyttet tilbake til lokalsykehuset i påvente av koronaroperasjonen. Dag 14 fikk pasienten nye smerter og EKG-forandringer forenlig med okkludert venstre fremre koronararterie. Han ble på ny overflyttet til Oslo universitetssykehus, Ullevål, der det for tredje gang ble påvist stenttrombose. Okklusjonen ble åpnet med ballongdilatasjon uten ny stentimplantasjon. Han fikk ufraksjonert heparin og abciximab under prosedyren. En time etter avsluttet prosedyre tilkom spontanblødninger fra nese, gastrointestinalkanalen, urinveier og alle innstikksteder på kroppen. Blodprøvene viste nå trombocyttverdi $2 \times 10^{9} /$, som var en drastisk nedgang fra verdien målt tidligere samme dag på lokalsykehuset (187 $\times 10^{\%} /$ l) (fig 2). Troponin T-verdien var 3,2 $\mu \mathrm{g} / \mathrm{l}$ og hemoglobinnivået $13,1 \mathrm{~g} / \mathrm{dl}$, synkende til 9,8 g/dl. Abciximab ble øyeblikkelig seponert. Han fikk deretter totalt fire enhe- ter platekonsentrat, og man «nullet ut» klopidogrel. Ved denne behandlingen steg trombocyttene til ca. $60 \times 10^{9} / \mathrm{l}$ og deretter spontant til $136 \times 10^{9} /$ l. Etter stabilisering av situasjonen valgte man å gi heparin som kontinuerlig infusjon. Dette var vellykket. Trombocyttallet fortsatte å stige. Pasienten gjennomgikk koronaroperasjon med bruk av hjerte-lunge-maskin og heparin 20 dager etter første hjerteinfarkt. Han ble utskrevet til sitt lokalsykehus for videre oppfølging av koronarsykdom og mistenkt kreftsykdom. Tumoren $i$ urinblæren viste seg å være et lavgradig, malignt karsinom uten muskelinvasivitet, og radikalbehandling er under planlegging.

\section{Diskusjon}

Faktorer som er involvert i utvikling av stenttrombose kan være at pasienten har høy alder, diabetes mellitus, malign sykdom, nyresvikt, lav ejeksjonsfraksjon og mangelfull antitrombotisk behandling, men kan også skyldes lokale forhold som en udekket disseksjon eller en stent som ikke er fullt ut ekspandert (6). Hos denne pasienten kan omfattende og gjentatt stenting i samme område ha bidratt til økt risiko for stenttrombose. Intravaskulær ultralydundersøkelse kunne ha avdekket lokale forhold ved stenten. Hos denne pasienten ble dette ikke utført.

Mangelfull antitrombotisk behandling kan enten skyldes pasienten selv (avbrudd av igangsatt behandling) eller manglende respons på behandlingen. Klopidogrel er avhengig av metabolisering i lever via cytokrom P-450-systemet (CYP2C19) for omdanning til aktiv metabolitt. Manglende respons på behandling kan skyldes genetisk variasjon forårsaket av enkeltnukleotidpolymorfismer, som medfører reduserte nivåer av aktiv metabolitt (7). Pasienter med akutt koronarsyndrom som var bærer av minst ett CYP2C19-allel assosiert med redusert funksjon, viste seg å ha nedsatte nivåer av aktiv metabolitt i plasma og tre ganger økt risiko for stenttrombose (7). Interaksjon med medikamenter som også metaboliseres via CYPsystemet kan også påvirke aktiveringen av klopidogrel. Vår pasient ble gitt protonpumpehemmer sammen med klopidogrel. Protonpumpehemmere, og i særlig grad omeprazol, er vist å svekke den hemmende effekten av klopidogrel på blodplateaggregering. I retrospektive observasjonsstudier har man sett økt dødelighet hos pasienter som fikk protonpumpehemmere samtidig med klopidogrel sammenliknet med pasienter som ikke fikk denne kombinasjonsbehandlingen. Derfor har både det amerikanske og det europeiske legemiddelverket nylig advart mot å bruke protonpumpehemmere sammen med klopidogrel så fremt det ikke er absolutt nødvendig. Imidlertid fant man i en studie med over 13000 pasienter med akutt koronar-syndrom behandlet med platehemmerne klopidogrel eller prasugrel 
at samtidig bruk av protonpumpehemmere ikke ga noen effekt på kliniske hendelser (8). Det ser derfor ut til at denne legemiddelinteraksjonen sannsynligvis har mindre klinisk betydning enn først antatt.

Heparinindusert trombocytopeni eller trombocytopeni grunnet antistoffdanning mot abciximab ble oppfattet som sannsynlig forklaring på det raske trombocyttfallet $(9$, 10). Stabil koronar gjennomblødning måtte opprettholdes for å bevare pasientens pumpefunksjon i venstre ventrikkel. Det var viktig å avdekke årsaken til trombocytopenien, slik at pasienten kunne få antitrombotisk behandling frem til og under planlagt koronaroperasjon. Heparinindusert trombocytopeni skyldes antistoffer mot heparin-platefaktor 4-kompleks og inntrer som regel 4-10 dager etter oppstart med heparin, men kan også ses tidligere dersom pasienten har vært eksponert for heparin de siste 3-4 måneder. Trombocytopenien medfører sjelden trombocyttall $<15 \times 10^{9} / 1$. Spontanblødninger er derfor ikke vanlig. Derimot er venøs og arteriell trombosering et mer alvorlig problem ved heparinindusert trombocytopeni. Dette skyldes antakelig at heparin-platefaktor 4komplekset aktiverer trombocyttene (9).

Trombocytopeni er en kjent komplikasjon ved behandling med glykoprotein IIb/IIIahemmeren abciximab, ettersom det kan dannes antistoff (humant antikimært antistoff, HACA) mot trombocyttene. Registerdata for over 12000 pasienter viste trombocyttfall til $<20 \times 10^{9} / 1$ hos opptil $5 \%$ ved førstegangsbruk og opptil $16,5 \%$ ved readministrasjon innen 30 dager, men klinisk betydningsfull blødning hos kun 2,3\% ved gjentatte administrasjoner (10). Trombocytopeni sekundært til abciximab vil vanligvis inntreffe innen 24 timer etter administrasjon, men har oppstått så tidlig som innen 30 minutter og så sent som en uke etter administrasjon. Trombocytopeni forekommer også i relasjon til bruk av andre glykoprotein IIb/IIIa-hemmere (eptifibatid, tirofiban), men sjeldnere og med raskere normalisering av trombocyttallet etter seponering. Trombocytopeni relatert til abciximabbruk ser ikke ut til å øke risikoen for nytt trombocyttfall ved bruk av andre glykoprotein IIb/IIIahemmere ved en senere anledning (11).

Alternativ antikoagulasjonsbehandling vil $\mathrm{i}$ et tilfelle med kontraindikasjon mot heparin være bivalirudin, som også har ønsket effekt ved bruk av hjerte-lunge-maskin. Bruk av bivalirudin frem til og under koronaroperasjon ble vurdert, men dette er en kostbar behandling når behandlingen strekker ut i tid. Ut ifra det raske fallet i trombocytter relatert til tidspunktet for heparin og abciximabinfusjon, det svært lave trombocyttallet (under $10 \times 10^{9} / \mathrm{l}$ ), den kraftige blødningsreaksjonen og den økte risikoen forbundet med tidlig readministrering av abciximab fant man det overveiende sannsynlig at årsaken til trombocytopenien var sekundær til abciximabinfusjonen.

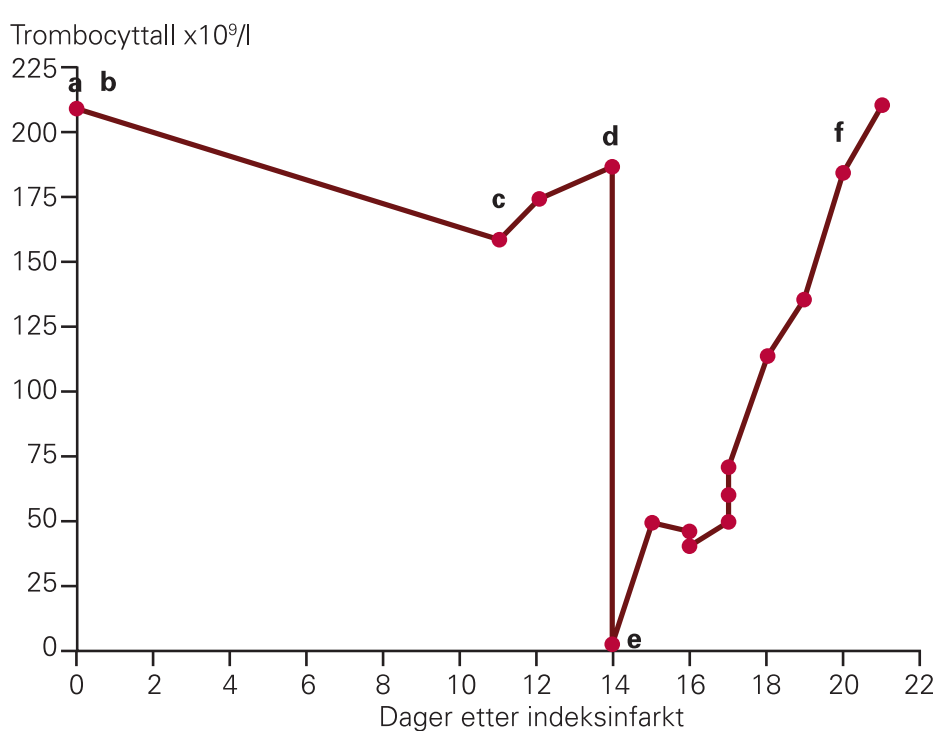

Figur 2 Figuren viser forløpet av trombocyttallet (ordinat) hos pasienten i dager (abscisse) etter hospitalisering første gang for akutt ST-hevningsinfarkt. Linjen viser mellom målinger. a) PCI av akutt ST-hevningsinfarkt (ufraksjonert heparin gis intravenøst), b) Stentrombose første døgn, ny PCl (ufraksjonert heparin og abciximab gis intravenøst), c) Ny innleggelse med stenttrombose (andre gang), ny PCl (ufraksjonert heparin gis intravenøst), d) Ny innleggelse med stenttrombose (tredje gang), ny PCl (ufraksjonert heparin og abciximab gis intravenøst), el Massiv blødning og fall i trombocytter en time etter PCl. Pasienten får trombocyttkonsentrat, f) Pasienten blir koronaroperert med bruk av hjerte- og lungemaskin og pågående heparininfusjon

\section{Konklusjon}

Vår pasients hovedproblem var blødning, residiverende stenttromboser og alvorlig trombocyttfall, og sykehistorien illustrerer hvor komplisert behandlingen av slike pasienter kan være. Den viser at kirurgi alltid bør vurderes som alternativ til gjentatte perkutane koronare intervensjoner og komplikasjoner ved denne prosedyren. Også problemer knyttet til årsak og behandling av stenttromboser blir her illustrert. Man må være oppmerksom på faren for trombocytopeni ved bruk av abciximab, spesielt ved tidlig readministrering innen 30 dager. Pasienter som har fått trombocytopeni som sannsynlig følge av abciximab, bør unngå dette medikamentet i fremtiden og må derfor vurderes for annen antitrombotisk behandling.

Pasienten har gitt samtykke til at artikkelen blir publisert.

Oppgitte interessekonflikter: Ingen

Litteratur

1. European Society of Cardiology. Management of acute myocardial infarction in patient present with persistent ST-segment elevation. Eur Heart J 2008; 29: 2909-45.

2. Wenaweser P, Rey C, Eberli FR et al. Stent thrombosis following bare-metal stent implantation: success of emergency percutaneous coronary intervention and predictors of adverse outcome. Eur Heart J 2005; 12: 1180-7.

3. Vik-Mo H, Slette M, Hegbom K. Antitrombotisk behandling etter perkutan koronar intervensjon med stent. Tidsskr Nor Legeforen 2008; 128: $436-9$.
4. Zakarjia A, Kwaan HC. Bleeding and thrombosis in the cancer patient. Expert Rev Cardiovasc Ther 2003: 1: 271-81.

5. Bassand J-P, Hamm CW, Ardissino D et al. Guidelines for the diagnosis and treatment of non-STsegment elevation acute coronary syndromes. Eur Heart J 2007: 28: 1598-660.

6. Stähli B. Drug-eluting stent thrombosis. Ther Adv Cardiovasc Dis 2009; 3: 45-52.

7. Mega JL. Cytochrome P-450 polymorphisms and response to clopidogrel. N Engl J Med 2009; 360: 354-62.

8. O'Donoghue ML, Braunwald E, Antman EM et al. Pharmacodynamic effect and clinical efficacy of clopidogrel and prasugrel with or without a proton-pump inhibitor: an analysis of two randomised trials. Lancet 2009: 374: 989-97.

9. Warketin TE, Kelton JG. Temporal aspects of heparin induced thrombocytopenia. N Engl J Med 2001; 344: 1286-92.

10. Dery JP, Braden GA, Lincoff AM et al. Final results of the ReoPro readministration registry. Am J Cardiol 2004; 93: 979-84

11. Said SM, Hahn J, Schleyer E et al. Glycoprotein Ilb/ Illa inhibitor-induced thrombocytopenia - diagnosis and treatment. Clin Res Cardiol 2007: 96: 61-9.

Manuskriptet ble mottatt 23.3. 2009 og godkjent 17.12. 2009. Medisinsk redaktør Siri Lunde. 